\title{
O PROCESSO DE GESTÃO E SUA APLICABILIDADE NO CONTEXTO ESCOLAR
}

\author{
THE MANAGEMENT PROCESS AND ITS APPLICABILITY IN THE SCHOOL \\ CONTEXT
}

\section{Elias Oliveira Costa ${ }^{\mathrm{I}}$}

RESUMO: O presente trabalho cujo tema é "O processo de gestão democrática e sua aplicabilidade no contexto escolar”, traz como objetivo geral analisar como ocorreu o processo de construção da gestão democrática na escola campo da pesquisa. $\mathrm{Na}$ construção do processo democrático, buscamos ainda identificar os pontos positivos e negativos que permearam a definição desse processo. Os procedimentos metodológicos contemplam os princípios e técnicas da abordagem qualitativa da pesquisa bibliográfica que contemplou estudos sobre: a democracia e a democratização das escolas públicas, a Lei de Diretrizes e Bases da Educação Nacional (LDB), a Constituição Federal do Brasil de 1988 (CF) e a Lei estadual ordinária $\mathrm{d}^{\mathrm{n}}$ I.503 de 2010 , que trata da gestão democrática nas escolas estaduais. Os resultados da pesquisa permitiram concluir que, a decisão da escolha da equipe gestora, não foi uma decisão da comunidade escolar, e sim, uma decisão de governo. Algumas escolas passam pela por eleição da equipe gestora com a participação da comunidade escolar através do voto, entretanto, não é comum a participação da comunidade escolar nas decisões da gestão.

Palavras-chave: Educação. Escola. Gestão Democrática.

ABSTRACT: he present work, whose theme is "the process of democratic management and its applicability in the school context", has as a general objective to analyze how the process of construction of democratic management in the school field of research occurred. In the construction of the democratic process, we also sought to identify the positive and negative points that permeated the definition of this process. The methodological procedures contemplate the principles and techniques of the qualitative approach of the research, being a case study. We used bibliographical research and field research. The

\footnotetext{
I Graduado em Educação física e mestre em Ciências da Educação e filiado ao Núcleo de Educação Étnico Racial da Secretaria de Estado da Educação do Amapá.E-mail: sailer4elias@gmail.com.
} 
bibliographical research included studies on: democracy and democratization of public schools, the Law on the Guidelines and Bases of National Education (LDB), the Federal Constitution of Brazil of 1988 (CF), and the Ordinary State Law no. 1.503 of 2010, Which deals with democratic management in state schools. Field research was conducted through questionnaires applied to the school management team and the school community. The results of the research allowed to conclude that, the decision of the selection of the management team, was not a decision of the school community, but a decision of the government. The school was elected by the management team with the participation of the school community through voting, however, it is not common for the school community to participate in management decisions.

Key-words: Education. School. Democratic Management.

\section{INTRODUÇÃO}

Esse estudo partiu do princípio de que a gestão das escolas públicas deve ser compartilhada com os demais sujeitos da comunidade escolar. Pois, de acordo com Cury (1997) a gestão pensada de forma democrática, pode adquirir uma dimensão muito diferente daquela associada à ideia de comando. Isto significa que se pode administrar por meio do diálogo e do envolvimento do coletivo. A participação e o exercício da cidadania no campo educacional, e mais especificamente na gestão da escola, estão ligados a um processo mais amplo de extensão da cidadania social à cidadania educacional, e, portanto, ligado à sua função social.

Diante disso, Cury (1997) recomenda que a gestão democrática seja instituída por meio da criação de conselhos deliberativos, eleição para diretores e da necessidade de construção coletiva do projeto político-pedagógico. Dessa forma, o estudo partiu da seguinte problemática: De que forma o processo de gestão democrática foi construído e está sendo conduzido nas escolas públicas?

O estudo teve como objetivo analisar como ocorreu o processo de construção da gestão democrática procurando elucidar a partir do conhecimento da comunidade escolar qual a concepção de gestão democrática, caracterizando ainda a forma sistemática do papel do diretor frente as novas exigências educacionais para a concretização de uma gestão 
efetivamente democrática e autônoma. Nessa construção do processo democrático, buscouse ainda.

\section{A GESTÃO DEMOCRATICA NAS ESCOLAS PÚBLICAS}

Em se tratando da educação pública nos últimos anos, considera-se indispensável relembrar as lutas históricas para a institucionalização da gestão democrática como princípio da educação, que foi inscrita na Constituição Federal Brasileira de 1988, após forte pressão dos educadores que participaram da IV Conferência Brasileira de Educação (CBE), em 1986, oportunidade em que escreveram uma Carta conhecida como "Carta de Goiânia”, a qual solicitava que fossem inseridos na Constituição vinte e um princípios básicos que atualmente entravam a efetiva democratização da sociedade.

Porém, o texto da Constituição Federal Brasileira de 1988 resumiu toda a solicitação dos educadores organizados, na simples expressão "gestão democrática do ensino público na forma da lei”. A Lei de Diretrizes e Bases da Educação Nacional (LDBEN) de 1996, que é a Lei da educação no país, em seu art. I4, também só reafirmou o princípio da gestão

democrática, com a seguinte redação: "I - participação dos profissionais da educação na elaboração dos projetos pedagógicos da escola" e II - a "participação das comunidades escolar e local em Conselhos Escolares ou equivalentes". No art. is destaca-se "os sistemas de ensino assegurarão às unidades escolares públicas de educação básica que os integram progressivos graus de autonomia pedagógica e administrativa e de gestão financeira, observadas as normas gerais de direito financeiro público" (BRASIL, I996, p. 8).

A elaboração do processo de gestão democrática nas escolas públicas insere-se no contexto da educação brasileira a partir de 1996, com a Criação da Lei de Diretrizes e Bases da Educação Nacional, Lei no. 9.394/96 que no seu Art. 15, afirma que "Os sistemas de ensino assegurarão às escolas públicas de educação básica que os integram progressivos graus de autonomia pedagógica e administrativa e da gestão financeira observada às normas gerais do direito financeiro público” (BRASIL, I996, p. 44). 
A democracia tem se revelado com significados e conceitos diferenciados em muitos espaços e em diferentes formas, na educação, por exemplo, modismos que tomam conta da educação pública e afirmam serem democráticos. Monteiro (2007) explica:

A palavra democracia é polissêmica, podendo, pois, possuir vários significados, dependendo dos interesses particulares de quem a encampa, moldando o discurso democrático a diferentes situações e pode ser utilizada até para designar coisas antagônicas. Os políticos brasileiros, por exemplo, só consideram antidemocráticos os outros. Mas uma coisa é comum: falar em democracia envolve sempre algo de positividade, de liberdade (MONTEIRO, 2007, p. 55).

Nesse contexto, moldam-se os discursos democráticos, dependendo dos interesses particulares. No Brasil, nos países da Europa e em outros países latino-americanos, os partidos de esquerda e os partidos mais progressistas têm assumido a bandeira da democracia como valor universal; no caso do Brasil essa bandeira se fortaleceu devido ao longo período de ditadura militar no país, que perdurou por vinte e um anos (1964 - 1985). Entretanto, as críticas a esse modelo são de ordem, principalmente, capitalista, que propagam "a ideologia do Estado neutro, a serviço do bem comum, o que se constitui numa falácia” (MONTEIRO, 2007, p. 56).

De acordo com Coutinho (2002), a democracia deve ser vista em um panorama mais amplo e não somente como um valor universal, representada através das eleições diretas livres, como se automaticamente essas relações se transformassem. Segundo o autor, "o que tem valor universal é esse processo de democratização que se expressa, essencialmente, numa crescente socialização da participação política" (COUTINHO, 2002, p. 17).

Souza (2009), ao tratar sobre o conceito de gestão democrática, faz uma articulação entre a escola pública, a política, o poder e a democracia e identifica alguns elementos que na sua visão: possibilitaram a construção de um conceito de gestão escolar democrática, reconhecendo-a como um processo político que é mais amplo do que apenas as tomadas de decisão e que é sustentado no diálogo e na alteridade, na participação ativa dos sujeitos do universo escolar, na construção coletiva de regras e procedimentos e na constituição de canais de comunicação, de sorte a ampliar o domínio das informações a todas as pessoas que atuam na/sobre a escola (SOUZA, 2009, p.136). 
A conquista de uma democracia direta e participativa deve começar na escola, como um aprendizado, sendo, por isso, importante a participação e a abertura de espaços organizados de participação no seu interior, para que os sujeitos escolares que estão envolvidos nos processos possam debater e tomar suas decisões.

\section{PARTICIPAÇÃO, AUTONOMIA E DESCENTRALIZAÇÃO COMO MECANISMOS POTENCIALIZADORES DA DEMOCRATIZAÇÃO.}

Três princípios são de extrema importância para se materializar a construção de uma gestão democrática, sendo:

a) O princípio da autonomia - requer vínculos mais estreitos com a comunidade educativa, basicamente os pais, as entidades e as organizações paralelas à escola. A presença da comunidade na escola, especialmente dos pais, tem várias implicações. Prioritariamente os pais e outros representantes participam do Conselho da Escola da Associação de Pais e Mestres para preparar o projeto pedagógico curricular e acompanhar e avaliar a qualidade dos serviços prestados (LIBÂNEO, 2004, p. 144).

A autonomia escolar na concepção democrática é, para Barroso (2013, p. 26-27), “um campo de forças, onde se confrontam e se equilibram diferentes detentores de influência (interna e externa) dos quais se destacam: o governo, a administração, professores, alunos, pais e outros membros da sociedade local". E essa coletividade se edifica na "confluência de várias lógicas e interesses, sejam políticos, gestionários, profissionais e pedagógicos (BARROSO, 2013, p.167).

A autonomia escolar tão defendida nos discursos oficiais como diretriz de uma política de governo exige a superação da centralização e a uniformização. É necessário que os sistemas se organizem para que as estruturas formais do sistema permitam um novo tipo de relacionamento, com a participação ativa das escolas dialogando com os sistemas de educação, a partir das suas realidades (MENDONÇA, 200o).

Barroso (2013) afirma que as escolas são espaços privilegiados para o diálogo e a construção da sua identidade e autonomia. É um dos principais mecanismos apontados 
como momentos de expressão coletiva da comunidade escolar na busca da sua identidade e de sua autonomia. O autor ainda nos revela que a autonomia pressupõe a liberdade (e capacidade) de decidir, ela não se confunde com a "independência", assim, a autonomia é um conceito relativo.

b) O princípio da participação - Atua como um dos principais mecanismos de democratização, não é um conteúdo que se possa transmitir, mas uma mentalidade e um comportamento com ele coerente. É uma vivência coletiva de modo que somente se pode aprender na práxis grupal, ou seja, só se aprende a participar, participando. A participação é então, entendida como uma necessidade humana e como um elemento central da vida política contemporânea (BORDENAVE, 2013).

O significado de participação possui sentidos diferenciados "incluindo, desde comunicar, anunciar, informar e fazer saber, até tomar-se parte e associar-se (WERLE, 2003, p. 19). Nesse sentido, a participação supõe a relação entre sujeitos autônomos que trocam experiências, vivências, que estabelecem diálogo e que em grupo constroem o conhecimento e se reconstroem. É um mecanismo importante para a concretização das finalidades da educação e a implantação da gestão democrática que surgiu no campo das relações sociais em meados de 1980 como uma forma de mediação para combater as posturas autoritárias e hierárquicas dos diretores de escola advindas da teoria clássica da administração na década de 1970 (PARO, 2005; ADRIÃO, 2006).

Embora não exista uma única forma de inserir um sistema gestão participativa, é possível identificar alguns princípios, valores e prioridades, na organização efetiva dessa gestão. Libâneo (2004, p.79), afirma que: A participação é o principal meio de se assegurar a gestão democrática da escola, possibilitando o envolvimento de profissionais e usuários no processo de tomada de decisões e no funcionamento da organização escolar. Além disso, proporciona um melhor conhecimento dos objetivos e metas, da estrutura organizacional e de sua dinâmica, das relações da escola com a comunidade, e favorece uma aproximação maior entre professores, alunos, pais.

Para o autor, o conceito de participação alicerça-se no de autonomia, que significa a competência das pessoas e dos grupos de dirigirem a sua própria vida. Gadotti (200I, p.47), 
afirma que a autonomia se refere à criação de novas relações sociais, que se opõem às relações autoritárias existentes. Sendo o oposto da uniformização, ela admite a diferença e supõe a parceria. Por esse motivo, uma escola autônoma não atua de forma isolada, mas em constante intercâmbio com a sociedade.

c) O princípio da descentralização - tem sido cada vez mais incorporado pelas políticas públicas educacionais, que sem infringir as regras de harmonia do conceito, caracteriza-se como a não centralização da gestão autoritária.

Segundo Casassus (1995), a descentralização aumenta a probabilidade de haver uma maior participação dos envolvidos no processo educativo e uma maior eficácia na prática educativa devido a um maior controle social, aumentando a responsabilidade da equipe escolar. Neste contexto, o diretor escolar deve transformar-se em um motivador, incentivador e catalisador de ações que liguem a escola a outras escolas e à comunidade local, onde a unidade de ensino encontra-se inserida.

Parece existir um consenso sobre a necessidade de descentralização no campo da educação pública. É verdade que, se o centralismo administrativo foi um dos fatores que ajudou na implantação da burocracia e na modernização do Estado, no campo da educação esse fenômeno assumiu feições de exagero. Nos sistemas de ensino, o centralismo foi aumentado em um grau tão distante do necessário para permitir a racionalização dos processos administrativos que passou a ser um dos alvos principais das críticas que surgiram em torno da luta pela democratização da educação. É inegável que o centralismo administrativo permitiu a expansão da oferta educacional, mas, exacerbado, tornou a escola distante da comunidade em função do planejamento e da gestão serem realizados em níveis centrais.

Apesar da descentralização não ser intrinsecamente democratizante, é corrente a confusão conceitual sobre o tema, estabelecendo ligação direta entre a centralização e o autoritarismo, entre a descentralização e a democracia.

No universo da escola em estudo, percebe-se que muitas ações são decididas com a participação de todos os sujeitos que compõem a escola, como por exemplo, a realização das reuniões pedagógicas e os plantões, organizados para atender as famílias dos alunos, no 
compromisso de repassar aos seus familiares o rendimento educacional do aluno. $O$ professor tem a autonomia de como ele vai se dirigir aos pais ou responsável para lhe informar sobre a vida escolar de seu filho. Assim, também como o professor tem total autonomia de elaborar suas atividades voltadas à docência, compete somente a coordenação pedagógica orientar e supervisionar seu trabalho.

A gestão democrática na escola, na lócus da pesquisa, pode-se afirmar que ela está na sua fase inicial, pois muito ainda preciso ser conquistado, principalmente em relação a transparência e as decisões da aplicabilidade dos recursos financeiros que a escola dispõe, uma vez que muitos recursos não são de conhecimento de todos.

\section{EXIGÊNCIAS EDUCACIONAIS PARA UMA GESTÃO DEMOCRATICA E O PAPEL DO DIRETOR}

Segundo Lucky (2005), é no ano de 1980 que o movimento em favor da Descentralização e da democratização da gestão das escolas públicas é iniciado. A Constituição Federal do Brasil, aprovada no ano de 1988, consolida a gestão democrática nos sistemas públicos de ensino, estabelecendo, nos seus artigos 205 e 206, que a educação brasileira, direito de todos e dever do Estado e da família, seria promovida e incentivada com a colaboração da sociedade, visando o pleno desenvolvimento da pessoa, seu preparo para o exercício da cidadania e sua qualificação para o trabalho.

De acordo com a autora Lucky (200o), a escola, ao movimentar-se da administração escolar para a gestão escolar, deixa de garantir a formação competente para que os alunos se tornem cidadãos participativos da sociedade, oferecendo a esses educandos oportunidade para que possam aprender para compreender a vida, a sociedade e a si mesmos, e passa a ser vista não como uma entidade autoritária e paternalista de responsabilidade do Governo, mas como uma organização viva, caracterizada por uma rede de relações de todos que nela atuam ou interferem.

A autora relata quando a escola deixa de desempenhar o seu papel que é de formar pessoas participativas, críticas e formadoras de opiniões perante a sociedade na qual ele 
vive, a escola deve se reconhecida como uma instituição participativa e autônoma, onde prevalece a coletividade e a participação de toda a comunidade escolar em busca de um só objetivo, uma educação de qualidade.

O diretor da escola tem papel primordial, é peça fundamental na ação do trabalho coletivo, pois competirá a ele promover o ambiente de fraternidade, de respeito, de diálogo e de responsabilidade entre os alunos e a comunidade escolar, este mesmo ambiente. Constituir uma permanente conversa entre a direção e todos os segmentos da escola é fundamental, pois neles repousa a possibilidade de viabilizar um ensino de qualidade.

O gestor passa a ser também um educador, mais sabemos que nem sempre isto acontece, alguns diretores não estão nem aí pra educação, não tem o compromisso, a responsabilidade com o trabalho, muito diretores de escolas não tem formação acadêmica na área da educação e é por esse motivo que a educação pública brasileira está um caos. Sabemos que cabe a diretor a ação de garantir a efetivação da função educativa que é a motivo primordial da escola.

Segundo Líbano (20or) a tarefa dos gestores educacionais é dirigir e coordenar o andamento dos trabalhos, o clima do trabalho, a eficácia na utilização dos recursos e os meios, em função dos objetivos da escola. A democracia enquanto valor universal é prático de colaboração recíproca entre grupos e pessoas é um processo globalizante que, tendencialmente, deve envolver cada indivíduo na plenitude de sua personalidade (PARO, 200I, p.25).

Analisar a escola, como uma grande sinfonia, serve para fortalecer as discussões a respeito da atuação gestora democrática. O papel do gestor é simbolizado por um maestro, considerando que o maestro/gestor é quem deve ter a função de orientar seus músicos/educadores.

Demonstrar tal problemática remete-se, em uma questão central no âmbito da teoria e da prática pedagógica gestora, a relação assim, entre conteúdo e forma, à qual o 
conhecimento é sistematizado e aplicado no seu momento crucial de prática, onde todos os caminhos trilhados, resultantes das discussões frisadas no período em que se esteve na escola-campo subsidiaram os caminhos para uma real compreensão da estrutura organizacional de uma escola pública.

Observou-se no decorrer das ações dos docentes que a criticidade é um fator constante nas atitudes dos mesmos. Muitas vezes observaram-se professores ressaltando a falta de participação de pais nas reuniões e as suas insatisfações quanto ao rendimento escolar dos alunos. Tais dificuldades poderiam ser sanadas, não somente com um envolvimento maior de pais e alunos no planejamento escolar como já foi colocado na questão anterior, mas com o exercício da autonomia, cumprimento de deveres e exigência de direitos (por parte da comunidade) que uma escola cidadã e democrática requer. Para isto acontecer, cabe a instituição passar por algumas mudanças como enfatiza Gadotti e Romão (1997, p.35):

\footnotetext{
Mudança que implica deixar de lado o velho preconceito de que a escola pública é apenas um aparelho burocrático do Estado e não uma conquista da comunidade. A gestão democrática da escola implica que a comunidade, os usuários da escola, sejam os seus dirigentes e gestores e não apenas os seus fiscalizadores ou meros receptores dos serviços educacionais (GADOTTI E ROMÃO, 1997, p.35).
}

As ações de mudanças na educação deverão ser contínuas e que seja algo criado a partir de reflexões entre educadores e educandos, que não sejam originadas a partir de cobranças feitas pelo sistema educacional.

Em nenhum momento a escola tem a função de substituir a ação educadora da família, a escola é o complemento sistematizado da aprendizagem onde o estado provê meios para que de fato aconteça essa educação formal e sistematizada, segundo Campos (2008, p. 9), “[...] a família abandonou uma série de tarefas que antes realizava e que agora são assumidas por outras instituições”.

Diante disso, é possível perceber que a escola ainda necessita redimensionar a participação dos pais para os aspectos administrativos, para que estes não venham a fazer o papel de "cumpridores" do que já foi decidido pelos técnicos. Neste sentido, Gadotti e 
Romão (1997, p. 86) colocam que:

O planejamento na escola pretende superar a prática de atribuir a competência de planejar apenas a uma minoria de especialistas que, baseados numa suposta neutralidade política e científica, determinam os destinos da unidade escolar ou da educação como um todo, cabendo aos educadores, aos educandos, a todos os segmentos escolares e a comunidade educacional em geral, apenas a tarefa de cumprir o que foi por eles planejado (GADOTTI E ROMÃO, 1997, p. 86).

É possível perceber que a escola ainda necessita redimensionar a participação dos pais para os aspectos administrativos, para que estes não venham a fazer o papel de “cumpridores" do que já foi decidido pelos técnicos.

A família tem sido, é, e será a influência mais poderosa para o desenvolvimento da personalidade e do caráter das pessoas de nossa sociedade. E evidenciado no nosso tipo de organização social, o papel crucial da família quanto à proteção, afetividade e educação.

[...] é necessário um tempo maior para que as pessoas compreendam o sentido do trabalho coletivo e para que possam elaborar uma participação efetivamente política. A experiência participativa é incipiente e os indivíduos ainda não têm clareza sobre as limitações e possibilidades (ABRANCHES.2003, p. 73).

O dever da família com o processo de escolaridade e a importância da sua presença no contexto escolar é publicamente reconhecido na legislação nacional e nas diretrizes do Ministério da Educação aprovadas no decorrer dos anos 9o, especificamente na LDB 9394/96.

É importante ressaltar que a função educativa cabe não somente ao pai e a mãe, mas a toda esfera parental, segundo Aranha, (1995, p. 56)

A redução do tamanho da família, que ocorreu durante a industrialização, acentuou essa distinção de funções entre família e escola, embora suas esferas de ação sejam complementares, a redução do tamanho da família, que ocorreu durante a industrialização, acentuou essa distinção de funções. ARANHA, (1995, P. 56) 
Desse modo, é possível perceber que o processo de gestão implica, não somente fazer com que a comunidade participe, mas principalmente gerir esta comunidade onde entram os processos organizacionais em que se faz necessário coordenar toda uma equipe de trabalho para que esta realmente venha a assumir suas responsabilidades. Verifica-se que a diretora tem encontrado dificuldades em gerir sua comunidade.

Dentro deste novo modelo de gestão, surge a figura do líder participativo, ou o chamado, diretor-gestor que, obviamente, tem papel fundamental nesta nova estrutura, pelo acentuado grau de responsabilização na consecução dos resultados. A transformação vivenciada no ambiente escolar nasce no papel do líder. Ele motiva, incentiva, direciona, delega, conscientiza, mas, tudo isto no intuito de provocar uma mudança nos paradigmas do passado.

O princípio da participação implica no que é inevitável: a direção, que dentro da gestão democrática, promove de maneira significante à promoção da gestão coletiva. Isso fica claro quando no decorrer das observações realizadas pelo grupo no período em que esteve envolvido com a pesquisa de campo, principalmente na visita realizada nas dependências da escola e no contato (conversas informais) com os seus membros, verificou-se que a gestora tem dificuldades em fazer com que as responsabilidades sejam assumidas por todos da comunidade, como, por exemplo, quando se trata de participar nas decisões relacionadas as mudanças no calendário ou mesmo nas programações referentes as datas festivas, tomando atitudes e aplicando ordens que deveriam ser discutidas pela Equipe escolar.

A participação do aluno não pode ficar limitada a assistir aulas, mas deve ser ampliada e atingir outros campos do processo de ensino e aprendizagem como, por exemplo, nas reuniões do Conselho Escolar, posto que é este Conselho o responsável por muitas decisões que repercutem sobre o aluno e sua vida escola

A participação do aluno não pode ficar limitada a assistir aulas, mas deve ser ampliada e atingir outros campos do processo de ensino e aprendizagem como, por 
exemplo, nas reuniões do Conselho Escolar, posto que é este Conselho o responsável por muitas decisões que repercutem sobre o aluno e sua vida escola

É possível constatar que os alunos não participam das reuniões ocorridas na escola. Este fato evidencia o desconhecimento por parte da Coordenação pedagógica, já que cabe a esta fazer com que os alunos participem das reuniões da escola por meio de seus representantes de turma. Evidencia Libâneo (2003, p.223) que este profissional deve, "criar as condições necessárias para integrar os alunos na vida da escola, formas associativas e de participação em decisões etc”.

A liberdade de opinar sobre os assuntos tratados na escola faz parte dos princípios de autonomia da gestão democrática citado neste trabalho por Paro (200I), sendo assim, constata-se neste gráfico que a maioria dos alunos ainda possui um grau escasso de participação e criticidade sobre o trabalho escolar. Tal situação demonstra a necessidade dos professores e coordenação trabalharem para que os alunos sejam situados como sujeitos ativos e participativos do processo ensino-aprendizagem, pois numa gestão democrática, a concepção de cidadão é fator essencial.

Possibilitar oportunidades de diálogo, ouvir e compreender os alunos são o primeiro passo para desencadear um movimento de participação popular na escola, afinal, a gestão democrática volta-se tanto para o coletivo como para o individual, onde as necessidades devem ser atendidas.

Por outro lado, não basta instituir um conselho escolar com a participação dos sujeitos citados, mesmo com atribuições deliberativas, se este conselho ficar sempre na dependência do gestor da escola para fazê-lo funcionar. Até porque o Conselho escolar necessita ser constituído sobre parâmetros que visem o exercício da democracia, como coloca Vasconcelos (2002, p.84) “Os conselhos escolares também representam importante espaço para a democratização da escola, através do trabalho entre os vários segmentos que a compõem”.

Atualmente, a complexidade das tarefas de gestão e organização da escola, o avanço 
teórico-prático da educação e da gestão, e a democratização das relações escolares começam a interferir na lógica tradicional. A organização e a gestão da escola passam a ser assunto dos diferentes segmentos que compõem as reuniões do Conselho com a participação da comunidade. Nesse cenário, questões como avaliação educacional, planejamento escolar, calendário, Projeto Político-Pedagógico, eleições, festas e muitas outras atividades e decisões contam com a participação cada vez maior dos pais, dos estudantes, dos professores e dos funcionários.

Sendo assim, o Conselho Escolar surge como um aliado na luta pelo fortalecimento da unidade escolar e pela democratização das relações escolares. Segundo a Lei n 9.394/96 em seu Art. I4, inciso II:

\begin{abstract}
Os sistemas de ensino definirão as normas da gestão democrática do ensino público na educação básica, de acordo com as peculiaridades e conforme os seguintes princípios: (I (...); II) participação das comunidades escolares e locais em conselhos escolares ou equivalentes.
\end{abstract}

A participação do aluno não pode ficar limitada a assistir aulas, mas deve ser ampliada e atingir outros campos do processo de ensino e aprendizagem como, por exemplo, nas reuniões do Conselho Escolar, posto que é este Conselho o responsável por muitas decisões que repercutem sobre o aluno e sua vida escolar.

\title{
CONSIDERAÇÕES FINAIS
}

Conclui-se que no decorrer da pesquisa a maioria das escolas em seu processo administrativo e pedagógico não dispõem de ações que a caracterize a democracia e participação. No decorrer deste estudo, podemos descobrir que alguns caminhos foram percorridos para que a escola venha a se tornar uma democracia. Primeiramente, faz-se necessário que toda comunidade escolar, não somente tenha a ciência da importância de uma gestão democrática, mas, principalmente, busque descobrir sobre os caminhos que devem ser percorridos para que ela realmente se efetive.

A gestão democrática está longe de ser concretizada porque é preciso trabalhar a questão cultural e social da comunidade escolar e conscientizar todos os membros que 
compõem a escola que cada um deve ter responsabilidade na implantação de uma gestão democrática e participativa na instituição, bem como a gestão da escola descentralizar as decisões que dizem respeito a escola.

As ações do diretor, mesmo em pequenos passos tenta transformar a de forma humana a gestão escolar em democrática e participativa através de projetos que envolva toda equipe escolar, comunidade e alunos. Mesmo não alcançando o seu objetivo que é a participação de todos na elaboração e na concretização dos trabalhos, as pequenas ações feitas agora podem ser exemplo para o futuro.

A direção da maioria das escolas busca administrar de forma a contribuir com o trabalho do docente, de forma a dar apoio pedagógico fortalecendo os laços de humanidade entre a equipe para melhorar a qualidade do ensino. Vencer alguns obstáculos faz parte de trabalho do gestor.

Para que as ações do gestor se tornem democrática é preciso que haja mais trabalho reflexivo sobre a democratização das escolas municipais. Há uma necessidade muito grande de trabalhar esse foco para que no futuro se veja resultado das ações lançadas agora, ou seja, em se ter gestões democráticas e participativas em todas as escolas. O gestor deve orientar a sua equipe para que a mesma não se perca nos seus objetivos: que é de trabalhar para construção de uma sociedade mais justa e igualitária, onde as diferenças não interfiram no bom desenvolvimento de um trabalho coletivo.

$\mathrm{Na}$ questão da qualidade de ensino, a instituição trabalha com métodos construtivistas e tradicionais tanto por parte dos professores como da gestão. $\mathrm{Na}$ ação do gestor percebe-se que a mesma trabalha tentando envolver professores, funcionários, família e comunidade nas atividades da escola.

Apesar de compreender que a efetivação da gestão democrática na escola é um processo que requer a cada instituição uma longa caminhada de estudos e experiências, entende-se que o curso sobre esta temática não se conclui nos parâmetros optados por este trabalho, pela sua complexidade e necessidade de que novos horizontes sejam traçados, 
pretende-se ainda, em novos estudos, ampliar os conhecimentos sobre este processo de transformação, que resgata inicialmente as referências coletivas do ser humano e a convicção de que ele pode intervir no processo de construção histórica da sociedade através da democracia no campo educacional.

\section{REFERÊNCIAS}

ABRANCHES, Mônica. Colegiado Escolar - Espaço de participação da comunidade Ed. Cortez, 2003, São Paulo/SP.

ADRIÃO, T. Educação e Produtividade a Reforma do Ensino Paulista e a Desobrigação do Estado. São Paulo: Ed. Xamã, 2006.

ARANHA, Antônia Vitória Soares. Gestão e organização do trabalho escolar: novos tempos e espaços de aprendizagem, IN: OLIVEIRA. Maria Auxiliadora Monteiro, Gestão educacional: novos olhares, novas abordagens. Petrópolis, RJ: Vozes .2005,p.75-86

BARROSO, João. O reforço da autonomia das escolas e a flexibilização. Gestão Democrática da Educação: atuais tendências, novos desafios. 8 ed. São Paulo: Cortez, 2013.

BORDENAVE, J. O que é participação. 8aㅡ ed. São Paulo: Braziliense, 2013.

BRASIL. Lei de Diretrizes e Bases da Educação Nacional. no 9.394/96. Brasília: MEC, 1996.

. Lei 5692, de II de agosto de 1971, que "fixa diretrizes e bases para o ensino de Iㅇ e $2^{\text {o }}$ graus e dá outras providências”. Diário Oficial da União. Brasília, v.I, p. 6.377, de I2/o8/7I.

BRASIL. Constituição da República do Brasil, 1988.

BRASIL. Ministério da Educação. Lei 4.024, de 20 de dezembro de 1961, que "fixa diretrizes e bases da educação nacional”. Brasília, Diário Oficial da União, v.I, p.12-429, de 27/I2/6I.

Perspectivas da Gestão Escolar e Implicações quanto à Formação dos seus Gestores. Revista em Aberto, Brasília, v.17, n 72, fevereiro/junho 2000. 
CASASSUS, Juan. Tarefas da Educação. Campinas/SP: Autores Associados, I995.

CONGRESSO DE INICIAÇÃO CIENTÍfICA DA UFPe, 4. Anais eletrônicos. Recife: UFPe, 1996. Disponível em: 〈http://www.propesq.ufpe.br/ anais/anais.htm>. Acesso em: 2I jan. 1997.

CONSELHO FEDERAL DE EDUCAÇÃO. Parecer 252, de II de abril de 1969. Define o currículo mínimo e a duração para o curso de graduação em pedagogia. Disponível em: http: // www.inep.gov.br. Acesso em: 10/o7/2007.

COUTINHO, C. N. A democracia na batalha das ideias e nas lutas políticas no Brasil de hoje. In: FÁVERO, O, \& SEMERARO, G. (orgs). Democracia e Construção do Público no Pensamento Educacional Brasileiro. Petrópolis: vozes, 2002.

CURY, C. R. J. et al. Medo à liberdade e compromisso democrático: LDB e Plano Nacional de Educação. São Paulo: Editora do Brasil, 1997.

GADOTTI, Moacir. Concepção dialética da educação: um estudo introdutório. São Paulo: Cortez, 200I.

GADOTTI, M. e ROMÃO, J. E. (orgs.). Autonomia da escola : princípios e propostas. São Paulo: Cortez, 1997.

GIL, A. Como elaborar projetos de pesquisa. São Paulo :Atlas, 1987. Anos iniciais, Curitiba: Ibpex, 2008.

LIBÂNEO, José Carlos. Organização da Escola: teoria e prática. Goiânia: Alternativa, 2001.

LIBÂNEO, José Carlos. Educação escolar: políticas, estrutura e organização. São Paulo: Cortez, 2003.

LIBÂNEO, José Carlos. Organização e gestão da escola: teoria e prática. 5. ed. Goiânia: Alternativa, 2004.

LÜCK, Heloísa. A Gestão Participativa na Escola. Ed. 5. Petrópolis, RJ: Vozes, 2009 
LÜCK, Heloisa. Perspectivas da gestão escolar e implicações quanto a formação de seus gestores. Em Aberto. Brasília. V.17,n.72,p.1I-33.fev/jun 2000.

A escola participativa: o trabalho do gestor escolar. Petrópolis, RJ: Vozes, 2005.

MENDONÇA, E. F. A Regra e o Jogo: Democracia e patrimonialismo na educação brasileira. Campinas: UNICAMP, 2000.

MONTEIRO, Carlos Antônio Ferreira. Gestão democrática como processo de alteração estrutural. Revista Brasileira de Estudos Pedagógicos. Brasília, V.88, n. 219, p. 363-389, maio/ago. 2007.

NÓVOA, Antonio. Os professores e a sua formação. $2^{\underline{a}}$ ed. Lisboa Dom Quixote, 1991.

PARO, Vitor Henrique. Escritos sobre educação. São Paulo: Xamã, 20oI.

PARO, Vitor Henrique. Gestão democrática da escola pública. 3 ed. São Paulo: Ática, 2005.

SILVA, I. G. da. Pena de morte para o nascituro. O Estado de S. Paulo, São Paulo, i9 set. 1998. Disponível em: 〈http://www.providafamilia.org/pena_morte_ nascituro.htm>. Acesso em: I9 set. 1998 .

SILVA, José Maria da; SILVEIRA, Emerson Sena da. Apresentação de trabalhos acadêmicos: normas e técnica. Petrópolis, RJ: Vozes, 2007.

SOUZA, A. R. Explorando e construindo um conceito de gestão escolar democrática. Educação em Revista. Belo Horizonte. v.25, n.03, p.123-140, dezembro, 2009.

VEIGA, Ilma. Passos Alencastro. Escola: Espaço do Projeto Político Pedagógico. Campinas, São Paulo: Papirus, 1998.

VASCONCELlOS, C. S. Coordenação do Trabalho Pedagógico: do projeto político pedagógico ao cotidiano de sala de aula. São Paulo: Libertad, 2002.

WERLE, Flávia Obino Corrêa. Conselhos escolares: implicações na gestão da escola básica. Rio de Janeiro: DP\&A, 2003. 